\title{
Brief Report: Visual Processing of Faces in Individuals with Fragile X Syndrome: An Eye Tracking Study
}

\author{
Faraz Farzin $\cdot$ Susan M. Rivera $\cdot$ David Hessl
}

Published online: 28 April 2009

(c) The Author(s) 2009. This article is published with open access at Springerlink.com

\begin{abstract}
Gaze avoidance is a hallmark behavioral feature of fragile X syndrome (FXS), but little is known about whether abnormalities in the visual processing of faces, including disrupted autonomic reactivity, may underlie this behavior. Eye tracking was used to record fixations and pupil diameter while adolescents and young adults with FXS and sex- and age-matched typically developing controls passively viewed photographs of faces containing either a calm, happy, or fearful expression, preceded by a scrambled face matched on luminance. Results provide quantitative evidence for significant differences in gaze patterns and increased pupillary reactivity when individuals with FXS passively view static faces. Such abnormalities have significant implications in terms of understanding causes of gaze avoidance observed in individuals with FXS.
\end{abstract}

Keywords Face processing - Fragile X syndrome . FMRl gene - Eye tracking $\cdot$ Pupil reactivity

F. Farzin - S. M. Rivera

Department of Psychology, University of California, Davis, Davis, CA, USA

F. Farzin $(\varangle) \cdot$ S. M. Rivera

Center for Mind and Brain, University of California, Davis, 202 Cousteau Place, Suite 250, Davis, CA 95618, USA

e-mail: ffarzin@ucdavis.edu

S. M. Rivera · D. Hessl

Medical Investigation of Neurodevelopmental Disorders (M.I.N.D.) Institute, University of California, Davis, Medical Center, Sacramento, CA, USA

D. Hessl

Department of Psychiatry and Behavioral Sciences, University of California, Davis, Medical Center, Sacramento, CA, USA

\section{Introduction}

Fragile X syndrome (FXS) is the most common cause of inherited mental impairment (Crawford et al. 2001) and, to date, the most common known genetic cause of autism (Cohen et al. 2005). Although it is widely reported that gaze avoidance is a hallmark behavioral feature of FXS (Bregman et al. 1988; Cohen et al. 1991; Garrett et al. 2004), it remains unknown whether abnormalities in the visual processing of faces, including disrupted autonomic reactivity, may contribute to this observed social deficit.

Difficulty for individuals with FXS to establish and maintain eye-gaze during social interactions has been physiologically associated with markedly increased levels of cortisol or autonomic reactivity, suggesting that gaze aversion may be a coping mechanism that serves to reduce negative arousal (Belser and Sudhalter 1995; Hall et al. 2006; Hessl et al. 2002, 2006; Wisbeck et al. 2000). Secretion of cortisol, by means of a cascade of hormones along the hypothalamic-pituitary-adrenal (HPA) axis, involves feedback between several limbic structures, among which the amygdala plays a significant role, and which have been implicated in FXS (Binstock 1995; Hessl et al. 2004; Paradee et al. 1999).

Studies have shown that pupillary responses are regulated by the autonomic nervous system in part in response to level of emotional arousal (Bradley et al. 2008; Ekman et al. 1983; Hess and Polt 1960; Steinhauer et al. 2004). Pupil dilation has been linked with direct electrical stimulation of the amygdala (Gloor 1997) and neuroimaging findings have shown that amygdala activity is associated with an observer's pupil size as well as is sensitive to the pupil size of others (Demos et al. 2008; Harrison et al. 2006).

The goals of the current study were to examine number of fixations and gaze duration when individuals with FXS 
viewed photographs of faces with different emotional content, and to measure face-specific changes in pupil diameter as an index of autonomic arousal.

\section{Methods}

\section{Participants}

Participants included sixteen individuals with FXS (13 males) and sixteen typically developing (TD) controls (13 males). Individuals with FXS were confirmed to carry the FMRI full mutation as previously described (Saluto et al. 2005; Tassone et al. 2004). TD participants with no current or past psychiatric diagnoses were recruited from the community. Groups were individually matched on sex and chronological age $\left(t_{1,30}=-0.085, p>.05\right)$. At the time of testing, 10 individuals with FXS (8 males) were being treated with at least one class of medication; stimulant $(n=3)$, antipsychotic $(n=4)$, and anti-depressant $(n=5)$. One female control participant was being treated with an anti-hypertensive medication.

The Social Communication Questionnaire (SCQ; (Rutter et al. 2003) was used to evaluate symptoms of autism spectrum disorder in participants with FXS. Individuals with an SCQ score at or above $15(n=11,9$ males), or who raised clinical concerns for ASD (1 male), were referred for a more complete evaluation using the Autism Diagnostic Observation Schedule-Generic (ADOS-G; (Lord et al. 2002). Of these twelve, eight were diagnosed with Autistic Disorder and two were diagnosed with Pervasive Developmental Disorder-Not Otherwise Specified (PDD-NOS). Group characteristics are given in Table 1.

Table 1 Descriptive characteristics of the fragile X syndrome (FXS) and control groups (mean \pm SEM)

\begin{tabular}{lll}
\hline & FXS $(n=16)$ & TD $(n=16)$ \\
\hline Gender (M:F) & $13: 3$ & $13: 3$ \\
Chronological age (years) & $16.99 \pm 6.8$ & $17.14 \pm 6.3$ \\
Full scale IQ $^{\mathrm{a}}$ & $58.36 \pm 9.8$ & \\
SCQ & $15.45 \pm 7.51$ & \\
ADOS total $^{\mathrm{b}}$ & $10.46 \pm 4.07$ & \\
\hline
\end{tabular}

FXS Fragile $\mathrm{X}$ syndrome, TD typically developing, $S C Q$ social communication questionnaire-lifetime version, $A D O S$ autism diagnostic observation schedule

${ }^{\text {a }}$ Intellectual level was measured using the Weschler intelligence scales (Wechsler 2003), $n=14$ (two participants were not testable due to extremely low functioning)

b $n=13$
Apparatus and Stimuli

All stimuli were presented on a Tobii 1750 binocular eye tracker monitor. This eye tracking system consists of a high-resolution camera embedded in a 17 -inch monitor $(1,280 \times 1,024$ pixels resolution, $50 \mathrm{~Hz}$ sampling rate, average precision of $0.5^{\circ}$ of visual angle). There are several benefits of the Tobii 1750 system that make it conducive to testing individuals with developmental disorders, including approximately $20 \mathrm{~cm}$ of tolerance to head-motion in any direction without requiring any head restraints. Stimuli consisted of 60 colored photographs of adult human faces (equal numbers of males and females, different races and ethnicities) from the NimStim Face Stimulus Set (Tottenham 2002), each showing a calm, happy, or fearful expression, and 60 scrambled versions of the face images. Since it was critical that pupil responses following the onset of the face stimulus be independent of a pupillary light reflex, each face and its scramble were matched on mean luminance, and equivalence was confirmed using a photometer (Minolta, LS-100, Osaka, Japan). Face images subtended a $12.12^{\circ}$ by $17.19^{\circ}$ region (the size of an actual human face) when viewed from a distance of $60 \mathrm{~cm}$, and were presented on a standard 50\% grey background.

\section{Procedure}

The experimental protocol was approved by the Institutional Review Board at the University of California, Davis, and informed consent was obtained from all participants or their parents. Following a nine-point calibration, participants were told to view the pictures shown. Each trial consisted of a scrambled face presented for 1 second followed immediately by its matched face for 3 seconds. An inter-trial interval containing a uniform grey screen was shown for $0.5,1$, or $2 \mathrm{~s}$, randomly determined. The order of face presentation was randomized.

\section{Analyses}

Four area-of-interest (AOI) regions were defined for each face: eyes (including the eyebrows), nose, mouth, and other. Scrambled faces included a single AOI around the ellipse. Measures included number of fixations (where a fixation was defined as any data point within a 30 pixel radius for a minimum duration of $100 \mathrm{~ms}$ ) and proportion of looking time to each AOI region.

Each participant's pupil data, averaged from both eyes, were first filtered to remove any outlier values corresponding to blinks, loss of tracking data, or large changes in head position. Mean pupil diameter was calculated for 250-ms intervals across the trial duration, time-locked to the onset of the face stimulus. In order to determine the 
presence of a face-specific pupil response, relative change in pupil size was calculated by subtracting the mean pupil size during the scrambled face from the mean pupil size during each interval of the face presentation, and then "standardized" by dividing by the mean pupil size during the scrambled face. A similar pupil change was calculated for the intervals of the scrambled face, relative to the mean pupil size during the inter-trial interval.

\section{Results}

Individuals with FXS made significantly fewer fixations to the eye region of all faces (Fig. 1). A repeated-measures analysis of variance (RMANOVA) with AOI region, emotion, and group as independent variables and number of fixations as the dependent variable revealed a main effect of AOI region $[F(3,28)=16.74, p=0.001$, $\left.\eta^{2}=0.642\right]$. This effect was qualified by a significant
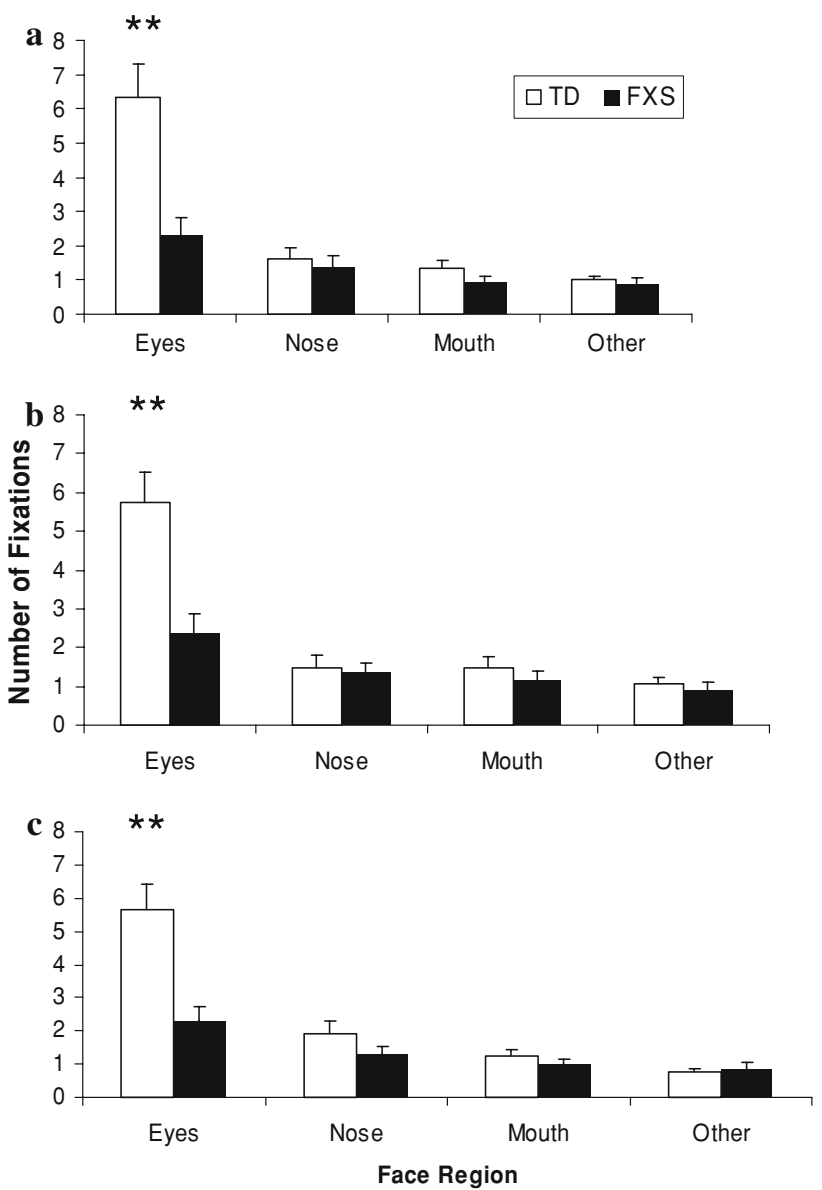

Fig. 1 Mean number of fixations to each AOI region by group for a calm, b happy, and c fearful faces. Double asterisk indicates significant difference between pairwise comparisons at the $p<.01$ level. Error bars represent SEM interaction between AOI region and group $[F(3,28)$ $\left.=5.12, p=0.006, \eta^{2}=0.354\right]$, such that individuals with FXS made fewer fixations to the eye region of faces compared to controls (Fig. 2). Individuals with FXS made fewer fixations to the face overall $[F(1,31)=8.926$, $p<0.01$ ), but no group difference was found for number of fixations made to the scrambled faces $[F(1,31)=3.154$, $p>0.05]$, suggesting that the fixation differences observed were specific to faces rather than generalizable to all images.

Individuals with FXS spent significantly less time looking at the eye region of all faces (Fig. 3). A RMANOVA with AOI region, emotion, and group as independent variables and proportion of gaze duration as the dependent variable revealed a main effect of AOI region $\left[F(3,28)=29.94, p=0.001, \eta^{2}=0.762\right]$ and a significant interaction between AOI region and group $\left[F(3,28)=3.56, \quad p=0.028, \quad \eta^{2}=0.274\right]$. Independent t-tests revealed that, across emotion conditions, individuals with FXS spent a smaller proportion of time looking at the eyes $[t(1,30)=3.28, p=0.003]$ and greater proportion of time looking at the nose $[t(1,30)=-2.58, p=0.015]$, compared to controls. No group difference was found for gaze duration to the scrambled faces $[F(1,31)=0.062$, $p>0.05]$.

Individuals with FXS demonstrated significantly greater pupillary reactivity in response to emotional faces, relative to controls (Fig. 4). A RMANOVA with interval (12), emotion, and group as independent variables and relative pupil change as the dependent variable resulted in a main effect of interval $[F(11,60)=4.66, \quad p=0.001$, $\left.\eta^{2}=0.134\right]$, such that, for all faces combined, there was an increase in pupil size (dilation) across time for both groups. A significant interaction between interval and emotion also was found $\left[F(22,9)=3.35, p=0.033, \eta^{2}=0.891\right]$, driven by pupil dilation to happy and fearful faces for both groups. A significant interaction between interval and group $\left[F(11,60)=4.72, p=0.001, \eta^{2}=0.136\right]$ showed that individuals with FXS demonstrated greater pupil dilation compared to TD controls. No group difference was found for change in pupil size to scrambled faces $[F(1$, 31) $=0.722, p>0.05]$.

An exploratory analysis revealed that, in individuals with FXS, but not controls, pupil dilation in response to the fearful faces was inversely correlated with number of fixations to the eyes of calm $(r=-0.550, p=0.027)$, happy $(r=-0.612, \quad p=0.012), \quad$ and fearful $(r=-0.641$, $p=0.007]$ faces, as well as proportion of gaze duration to the eyes of calm faces $(r=-0.579, p=0.019]$. There were no significant sex differences within either group on any of the above eye tracking measures. However, a lack of difference may also reflect limitations in statistical power as there were only three girls in each group. 
Fig. 2 Example fixation plots from one subject in each group (TD on left, FXS on right) for a single a calm, b happy, c fearful, and $\mathbf{d}$ scrambled face trial. The plot displays a static frame of fixation data for each image. Each fixation is illustrated with a circle where the radius represents the length of the fixation. Lines indicate eye movement scanpath
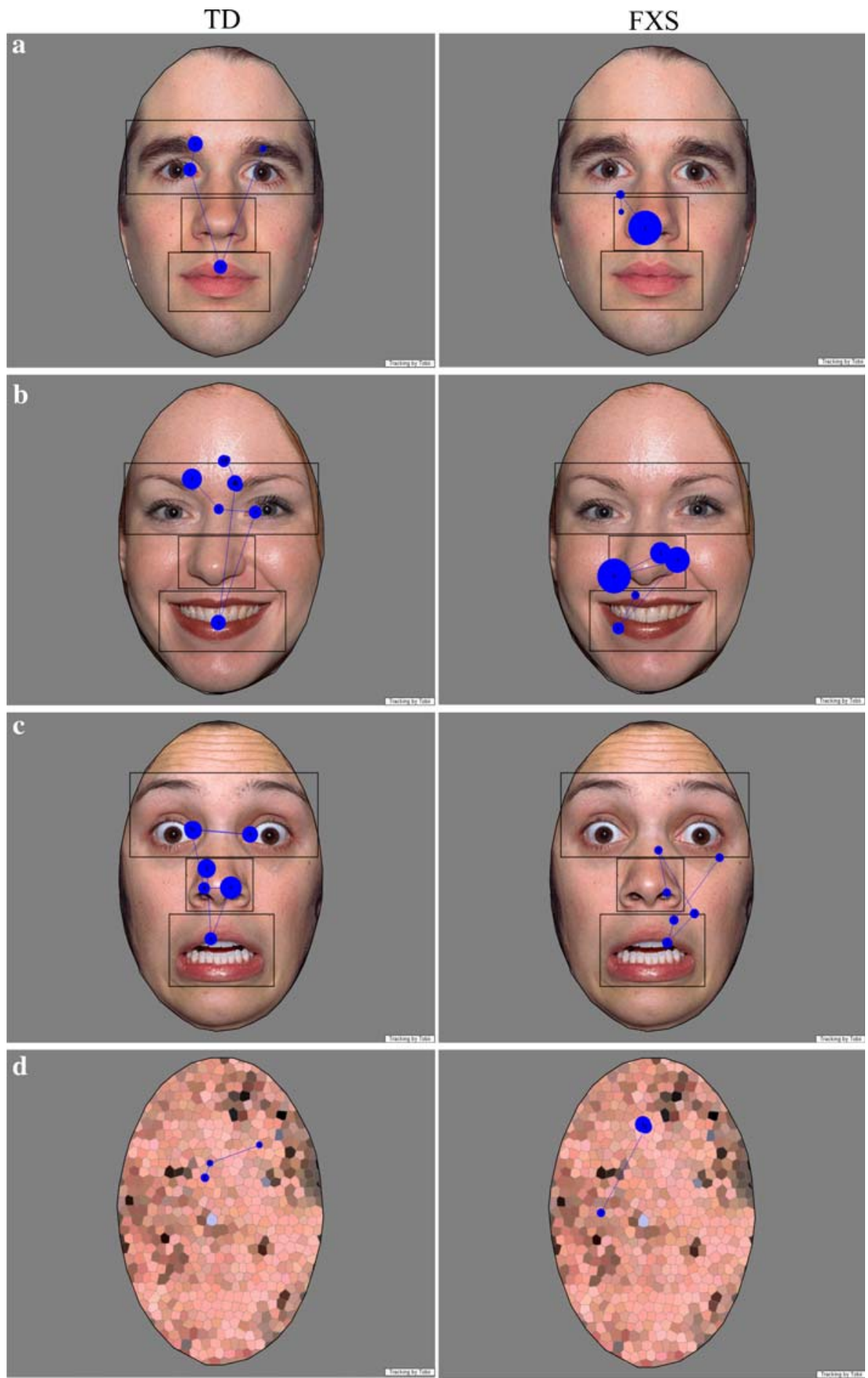

Finally, correlational analyses revealed no significant associations between symptoms of autism in individuals with FXS as measured by the SCQ and ADOS and number of fixations, gaze duration, and changes in pupil diameter in response to the faces. This finding is consistent with studies of gaze aversion in individuals with autism (Dalton et al. 2007; Klin et al. 2002; Speer et al. 2007).

\section{Discussion}

These findings reveal both qualitative and quantitative differences in the way that individuals with FXS visually process static human faces, and to our knowledge, are the first to utilize pupillometry as a measure of autonomic reactivity in individuals with FXS. Individuals with FXS demonstrated fewer fixations and less gaze time to the eye 


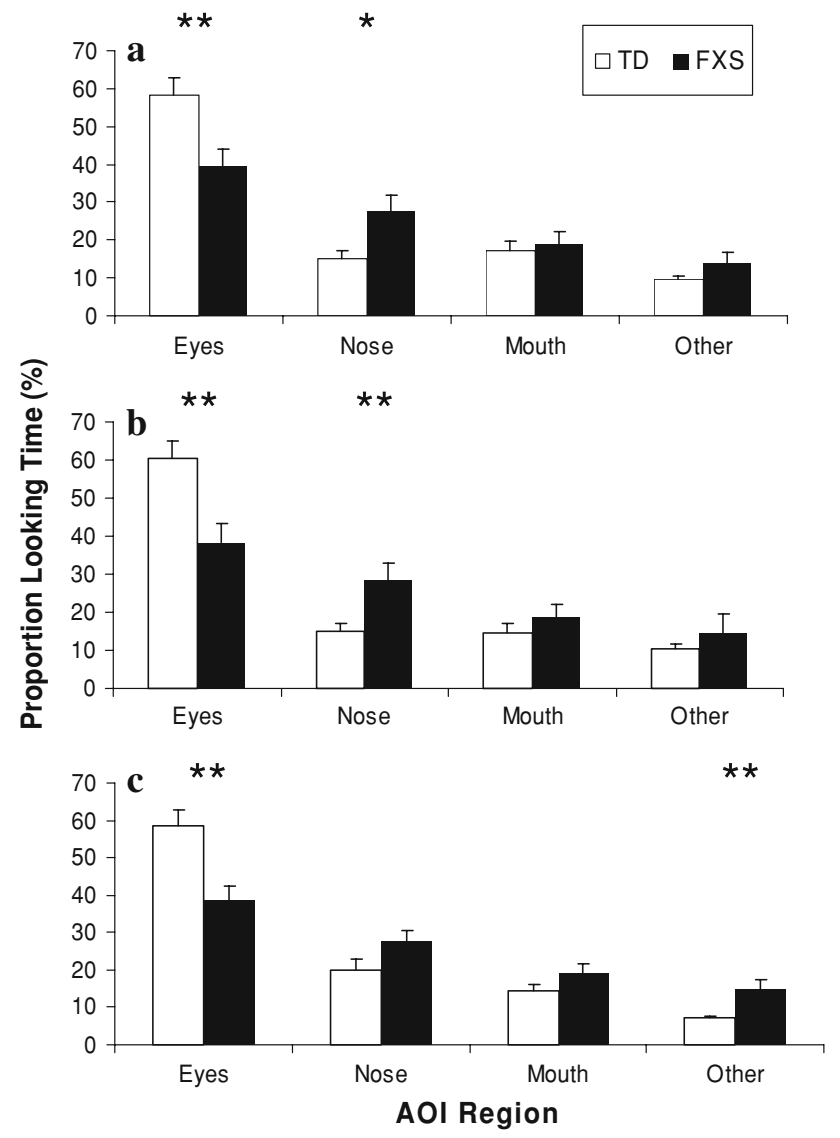

Fig. 3 Mean proportion gaze duration to each AOI region by group for a calm, b happy, and $\mathbf{c}$ fearful faces. Gaze durations are reported as percentages and error bars represent SEM. Asterisk and double asterisk indicate significant difference between pairwise comparisons at the $p<.05$ and $p<.01$ level, respectively

region of faces, and increased pupil reactivity to emotional faces, compared to controls. Importantly, pupil dilation in response to the fearful faces was inversely correlated with number of fixations to the eyes of all faces. This pattern was observed in both males and females with FXS, and was not significantly associated with severity of autism symptomology. Documentation of face processing differences is critical for developing treatment approaches aimed at alleviating the symptoms of social anxiety and has significant potential for use in assessing specific phenotypic outcomes following treatment in clinical research studies (Guastella et al. 2008).

Research has firmly established that FXS and autism are closely associated. Two to six percent of children with autism have the FMR1 mutation (Reddy 2005; Wassink et al. 2001) and approximately $30 \%$ of children with FXS are diagnosed with autism and an additional $20-30 \%$ have PDDNOS (Bailey et al. 2001; Harris et al. 2008; Kaufmann et al. 2004; Rogers et al. 2001). Researchers have hypothesized that the presence of autism symptoms in FXS exists on a spectrum, such that some individuals with FXS

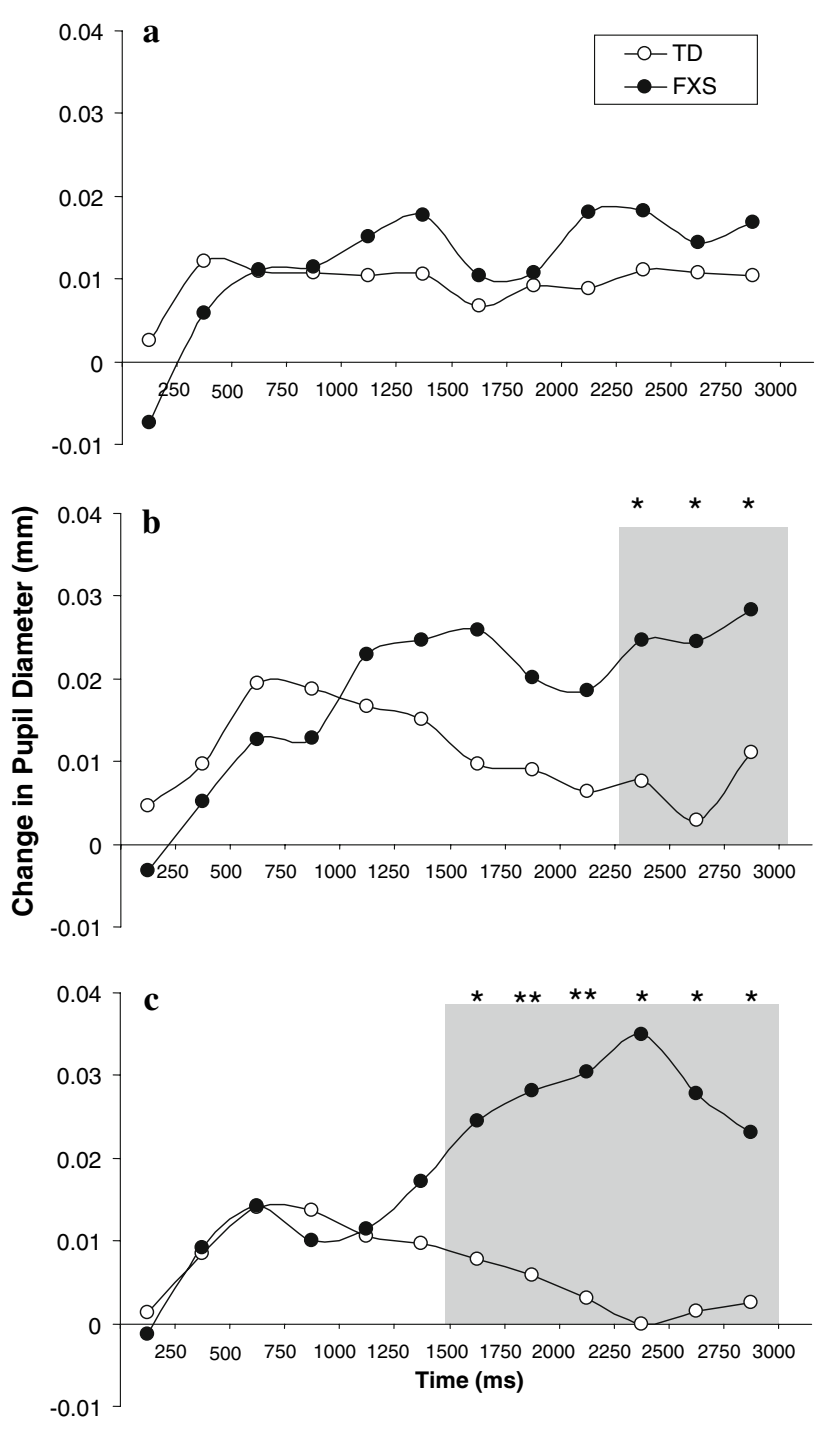

Fig. 4 Relative change in pupil diameter $(\mathrm{mm})$ between scrambled face slide to a calm, b happy, and c fearful faces, across 250-ms intervals, by group. Curves are time-locked to the onset of the face stimulus. Gray shaded region with asterisk or double asterisk indicates significant pairwise difference at the $p<.05$ and $p<.01$ level, respectively

who are also diagnosed with ASD may not be qualitatively different from those without ASD (D. B. Bailey et al. 2004; Lewis et al. 2006).

Our results are in line with research demonstrating that individuals with ASD spend a smaller percentage of time fixating the eyes (Klin et al. 2002; Merin et al. 2007; Pelphrey et al. 2002; Spezio et al. 2007), and thus support the argument that gaze aversion observed in idiopathic autism and in FXS may reflect similarities in underlying network dysfunctions (Belmonte and Bourgeron 2006). Several fMRI studies report reduced activity in the fusiform gyrus (FG) when individuals with autism perform face processing tasks (Dalton et al. 2005; Pierce et al. 
2004; Schultz et al. 2000), and fMRI in conjunction with eye tracking has shown that eye-gaze in individuals with autism is positively associated with increased activity and amygdala compared to controls (Dalton et al. 2005). It has therefore been suggested that gaze aversion may be a result of hyperactivation of the amygdala. On the cellular level, van Kooten et al. (2008) recently reported that the FG in post-mortem brains of patients with autism show significant reduction in neuron density and volume, which could provide a neurobiological explanation for the atypical activation of the FG observed in autism. Neuroimaging studies with individuals with FXS have shown reduced FG activation to forward faces and equal FG activation to angled faces, relative to controls (Garrett et al. 2004). Although our interpretations of a common pathophysiological pathway remain speculative until differences in the underlying neural circuitry can be better identified, they are consistent with clinical and research reports of individuals with FXS, with and without autism, becoming overly emotionally aroused and anxious during social situations and therefore averting gaze to facilitate reduction of arousal.

These results should be viewed in light of a few limitations. Including data from groups of individuals with idiopathic developmental delay or autism would help to specify the interpretations and implications of the findings. While our results establish that individuals with FXS exhibit abnormal fixation patterns when viewing static photographs of faces, suggesting that pictures of faces, particularly eyes, are inherently aversive, using dynamic social stimuli that resemble real-life social situations would extend these results. Future studies are required to investigate these findings as they relate to the function of specific brain areas involved in social behavior and emotion regulation.

Acknowledgments This work was supported by a grant from the National Institute of Mental Health to DH (MH77554). Thanks are given to the individuals who participated in this study and Alexis L. Schwartz for his assistance in developing specialized data analysis scripts. Data from this study were presented at the 11th International Fragile X Conference, St. Louis, MO, in July, 2008.

Open Access This article is distributed under the terms of the Creative Commons Attribution Noncommercial License which permits any noncommercial use, distribution, and reproduction in any medium, provided the original author(s) and source are credited.

\section{References}

Bailey, D. B. J., Hatton, D. D., Skinner, M., \& Mesibov, G. B. (2001). Autistic behavior, FMR1 protein, and developmental trajectories in young males with fragile $\mathrm{X}$ syndrome. Journal of Autism and
Developmental Disorders, 31, 165-174. doi:10.1023/ A:1010747131386.

Bailey, D. B., Roberts, J. E., Hooper, S. R., Hatton, D. D., Mirrett, P. L., \& Roberts, J. E. (2004). Research on fragile X syndrome and autism: Implications for the study of genes, environments, and developmental language disorders. In M. L. Rice, S. F. Warren, et al. (Eds.), Developmental language disorders: From phenotypes to etiologies (pp. 121-150). Mahwah, NJ: Lawrence Erlbaum Associates.

Belmonte, M. K., \& Bourgeron, T. (2006). Fragile X syndrome and autism at the intersection of genetic and neural networks. Nature Neuroscience, 9(10), 121-1225. doi:10.1038/nn1765.

Belser, R. C., \& Sudhalter, V. (1995). Arousal difficulties in males with fragile X syndrome: A preliminary report. Developmental Brain Dysfunction, 8, 270-279.

Binstock, T. C. (1995). Fragile $X$ and the amygdala: Cognitive, interpersonal, emotional and neuroendrocrine consideration. Developmental Brain Dysfunction, 8, 199-217.

Bradley, M. M., Miccoli, L., Escrig, M. A., \& Lang, P. J. (2008). The pupil as a measure of emotional arousal and autonomic activation. Psychophysiology, 45(4), 602-607. doi:10.1111/ j.1469-8986.2008.00654.x.

Bregman, J. D., Leckman, J. F., \& Ort, S. I. (1988). Fragile X syndrome: Genetic predisposition to psychology. Journal of Autism and Developmental Disorders, 18(3), 343-354. doi:10. 1007/BF02212191.

Cohen, D., Pichard, N., Tordjman, S., Baumann, C., Burglen, L., Excoffier, E., et al. (2005). Specific genetic disorders and autism: Clinical contribution towards their identification. Journal of Autism and Developmental Disorders, 35, 103-116. doi:10.1007/ s10803-004-1038-2.

Cohen, I. L., Vietze, P. M., Sudhalter, V., Jenkins, E. C., \& Brown, W. T. (1991). Effects of age and communication level on eye contact in fragile $\mathrm{X}$ males and non-fragile $\mathrm{X}$ autistic males. American Journal of Medical Genetics, 38(2-3), 498-502. doi:10.1002/ajmg.1320380271.

Crawford, D., Acuna, J. M., \& Sherman, S. L. (2001). FMR1 and the fragile $\mathrm{X}$ syndrome: Human genome epidemiology review. Genetics in Medicine, 3(5), 359-371. doi:10.1097/00125817200109000-00006.

Dalton, K. M., Nacewicz, B. M., Alexander, A. L., \& Davidson, R. J. (2007). Gaze-fixation, brain activation, and amygdala volume in unaffected siblings of individuals with autism. Biological Psychiatry, 61(4), 512-520. doi:10.1016/j.biopsych.2006.05. 019.

Dalton, K. M., Nacewicz, B. M., Johnstone, T., Schaefer, H. S., Gernsbacher, M. A., Goldsmith, H. H., et al. (2005). Gaze fixation and the neural circuitry of face processing in autism. Nature Neuroscience, 8, 519-526.

Demos, K. E., Kelley, W. M., Ryan, S. L., Davis, F. C., \& Whalen, P. J. (2008). Human amygdala sensitivity to the pupil size of others. Cerebral Cortex (New York, N.Y.), 18(12), 2729-2734.

Ekman, P., Levenson, R. W., \& Friesen, W. V. (1983). Autonomic nervous system activity distinguishes among emotions. Science, 221, 1208-1210. doi:10.1126/science.6612338.

Garrett, A. S., Menon, V., MacKenzie, K., \& Reiss, A. L. (2004). Here's looking at you, kid: Neural systems underlying face and gaze processing in fragile $\mathrm{X}$ syndrome. Archives of General Psychiatry, 61(3), 281-288. doi:10.1001/archpsyc.61.3.281.

Gloor, P. (1997). The temporal lobe and limbic system. New York: Oxford University Press.

Guastella, A. J., Mitchell, P. B., \& Dadds, M. R. (2008). Oxytocin increases gaze to the eye region of human faces. Biological Psychiatry, 63(1), 3-5. doi:10.1016/j.biopsych.2007.06.026.

Hall, S., DeBernardis, M., \& Reiss, A. (2006). Social escape behaviors in children with fragile $\mathrm{X}$ syndrome. Journal of 
Autism and Developmental Disorders, 36, 935-947. doi:10.1007/ s10803-006-0132-z.

Harris, S. W., Hessl, D., Goodlin-Jones, B., Ferranti, J., Bacalman, S., Barabato, I., et al. (2008). Autism profiles of males with fragile $\mathrm{X}$ syndrome. American Journal of Mental Retardation, 113(6), $427-438$.

Harrison, N. A., Singer, T., Rotshtein, P., Dolan, R. J., \& Critchley, H. D. (2006). Pupillary contagion: Central mechanisms engaged in sadness processing. Social Cognitive and Affective Neuroscience, 1, 5-17. doi:10.1093/scan/ns1006.

Hess, E. H., \& Polt, J. M. (1960). Pupil size as related to interest value of visual stimuli. Science, 132, 349-350. doi:10.1126/science.132. 3423.349 .

Hessl, D., Glaser, B., Dyer-Friedman, J., Blasey, C., Hastie, T., Gunnar, M., et al. (2002). Cortisol and behavior in fragile X syndrome. Psychoneuroendocrinology, 27(7), 855-872. doi:10. 1016/S0306-4530(01)00087-7.

Hessl, D., Glaser, B., Dyer-Friedman, J., \& Reiss, A. L. (2006). Social behavior and cortisol reactivity in children with fragile $\mathrm{X}$ syndrome. Journal of Child Psychology and Psychiatry, and Allied Disciplines, 47(6), 602-610. doi:10.1111/j.1469-7610. 2005.01556.x.

Hessl, D., Rivera, S. M., \& Reiss, A. L. (2004). The neuroanatomy and neuroendocrinology of fragile X syndrome. Mental Retardation and Developmental Disabilities Research Reviews, 10, 17-24. doi:10.1002/mrdd.20004.

Kaufmann, W. E., Cortell, R., Kau, A. S., Bukelis, I., Tierney, E., Gray, R. M., et al. (2004). Autism spectrum disorder in fragile X syndrome: Communication, social interaction, and specific behaviors. American Journal of Medical Genetics. Part A, 129A, 225-234. doi:10.1002/ajmg.a.30229.

Klin, A., Jones, W., Schultz, R., Volkmar, F., \& Cohen, D. (2002). Visual fixation patterns during viewing of naturalistic social situations as predictors of social competence in individuals with autism. Archives of General Psychiatry, 59(9), 809-816. doi:10.1001/archpsyc.59.9.809.

Lewis, P., Abbeduto, L., Murphy, M., Richmond, E., Giles, N., Bruno, L., et al. (2006). Cognitive, language, and socialcognitive skills of individuals with fragile $\mathrm{X}$ syndrome with and without autism. Journal of Intellectual Disability Research, 50(7), 532-545. doi:10.1111/j.1365-2788.2006.00803.x.

Lord, C., Rutter, M., DiLavore, P. C., \& Risi, S. (2002). Autism diagnostic observation schedule-manual. Los Angeles: Western Psychological Services.

Merin, N., Young, G. S., Ozonoff, S., \& Rogers, S. J. (2007). Visual fixation patterns during reciprocal social interaction distinguish a subgroup of 6-month-old infants at-risk for autism from comparison infants. Journal of Autism and Developmental Disorders, 37(1), 108-121. doi:10.1007/s10803-006-0342-4.

Paradee, W., Melikian, H. E., Rasmussen, D. L., Kenneson, A., Conn, P. J., \& Warren, S. T. (1999). Fragile X mouse: Strain effects of knockout phenotype and evidence suggesting deficient amygdala function. Neuroscience, 94(1), 185-192. doi:10.1016/S03064522(99)00285-7.

Pelphrey, K. A., Sasson, N. J., Reznick, J. S., Paul, G., Goldman, B. D., \& Piven, J. (2002). Neural basis of eye gaze processing deficits in autism. Brain, 128, 1038-1048. doi:10.1093/brain/ awh404.

Pierce, K., Haist, F., Sedaghat, F., \& Courchesne, E. (2004). The brain response to personally familiar faces in autism: Findings of fusiform activity and beyond. Brain, 127, 2703-2716. doi:10. 1093/brain/awh289.

Reddy, K. S. (2005). Cytogenetic abnormalities and fragile-X syndrome in autism spectrum disorder. BMC Medical Genetics, 6, 3. doi:10.1186/1471-2350-6-3.

Rogers, S. J., Wehner, E. A., \& Hagerman, R. J. (2001). The behavioral phenotype in fragile X: Symptoms of autism in very young children with fragile $\mathrm{X}$ syndrome, idiopathic autism, and other developmental disorders. Journal of Developmental and Behavioral Pediatrics, 22, 409-417.

Rutter, M., Bailey, A., \& Lord, C. (2003). Social communication questionnaire $(S C Q)$. Los Angeles: Western Psychological Services.

Saluto, A., Brussino, A., Tassone, F., Arduino, C., Cagnoli, C., Pappi, P., et al. (2005). An enhanced polymerase chain reaction assay to detect pre- and full mutation alleles of the fragile $\mathrm{X}$ mental retardation 1 gene. The Journal of Molecular Diagnostics, 7(5), 605-612.

Schultz, R. T., Gauthier, I., Klin, A., Fulbright, R. K., Anderson, A. W., Volkmar, F., et al. (2000). Abnormal ventral temporal cortical activity during face discrimination among individuals with autism and Asperger syndrome. Archives of General Psychiatry, 57, 331-340. doi:10.1001/archpsyc.57.4.331.

Speer, L. L., Cook, A. E., McMahon, W. M., \& Clark, E. (2007). Face processing in children with autism:effects of stimulus contents and type. Autism, 11(3), 265-277. doi:10.1177/1362361307076925.

Spezio, M. L., Adolphs, R., Hurley, R. S., \& Piven, J. (2007). Abnormal use of facial information in high-functioning autism. Journal of Autism and Developmental Disorders, 37(5), 929939. doi:10.1007/s10803-006-0232-9.

Steinhauer, S. R., Siegle, G. J., Condray, R., \& Pless, M. (2004). Sympathetic and parasympathetic innervation of pupillary dilation during sustained processing. International Journal of Psychophysiology, 52, 77-86. doi:10.1016/j.ijpsycho.2003.12.005.

Tassone, F., Hagerman, R. J., Garcia, A. D., Khandijian, E. W., Greco, C. M., \& Hagerman, P. J. (2004). Intranuclear inclusions in neural cells with premutation alleles in fragile $\mathrm{X}$ associated tremor/ataxia syndrome. Journal of Medical Genetics, 41, 1-3. doi:10.1136/jmg.2003.012518.

Tottenham, N., Borscheid, A., Ellertsen, K., Marcus, D. J., \& Nelson, C. A. (2002). Categorization of facial expressions in children and adults: Establishing a larger stimulus set. Paper presented at the Cognitive Neuroscience Society Annual Meeting.

van Kooten, I. A. J., Palmen, S. J. M. C., von Cappeln, P., Steinbusch, H. W. M., Korr, H., Heinsen, H., et al. (2008). Neurons in the fusiform gyrus are fewer and smaller in autism. Brain, 131, 987999. doi:10.1093/brain/awn033.

Wassink, T. H., Piven, J., \& Patil, S. R. (2001). Chromosomal abnormalities in a clinic sample of individuals with autistic disorder. Psychiatric Genetics, 11, 57-63. doi:10.1097/000414 44-200106000-00001.

Wechsler, D. (2003). Wechsler intelligence scale for children (4th ed.). San Antonio: Harcourt Assessment, Inc.

Wisbeck, J. M., Huffman, L. C., Freund, L., Gunnar, M. R., Davis, E. P., \& Reiss, A. L. (2000). Cortisol and social stressors in children with fragile X: A pilot study. Journal of Developmental and Behavioral Pediatrics, 21, 278-282. doi:10.1097/00004703200008000-00004. 